\title{
Conhecimento da população brasileira acerca da doação de órgãos e tecidos para transplantes
}

\author{
Knowledge of the brazilian population about the donation of organs and tissues for \\ transplantation \\ Conocimiento de la población brasileña sobre la donación de órganos y tejidos para \\ trasplantes
}

Camila Cella de Souza ${ }^{1 *}$, Elisa Kowalski Kologeski do Nascimento ${ }^{2}$, Alexander de Quadros ${ }^{3}$, Amanda Pereira Ferreira Dellanhese ${ }^{4}$, Simone Lysakowski ${ }^{5}$, Morgana Thais Carollo Fernandes ${ }^{6}$.

\section{RESUMO}

Objetivo: Avaliar o conhecimento e aceitação da população brasileira sobre o diagnóstico da morte encefálica (ME) e doação de órgãos e tecidos para transplantes. Métodos: Trata-se de um estudo observacional descritivo, transversal, realizado por conveniência, através da aplicação de um questionário online, pela Plataforma do Google Forms ${ }^{\circledR}$, tendo as perguntas embasadas nas leis regulamentares da doação de órgãos e tecidos para transplantes no Brasil. Resultados: Participaram da pesquisa 406 sujeitos, prevalecendo o sexo feminino $(73,60 \%)$, com faixa etária entre 18 e 30 anos $(45,80 \%)$, cursando o ensino superior $(33,20 \%)$ e autodeclarados católicos $(35,40 \%)$. Do total, $93,10 \%$ dos participantes se declararam favoráveis à doação de órgãos, apesar de $71,10 \%$ acreditar que exista a comercialização de órgãos e tecidos. Conclusão: Campanhas e informativos sobre o assunto devem ser intensificados, contendo informações claras e objetivas, a fim de elucidar a população frente ao tema, buscando assim aumentar o número de doadores efetivos no país.

Palavras-chave: Obtenção de tecidos e órgãos, Transplantes, Conhecimento, Opinião pública.

\section{ABSTRACT}

Objective: Evaluate the knowledge and acceptance of the Brazilian population on the diagnosis of brain death (BD) and organ and tissue donation for transplants. Methods: This is a descriptive, cross-sectional observational study, carried out for convenience, through the application of an online questionnaire, through the Google Forms ${ }^{\circledR}$ Platform, with questions based on the regulatory laws on organ and tissue donation for transplants in Brazil. Results: 406 subjects participated in the survey, with a predominance of females (73.60\%), aged between 18 and 30 years $(45.80 \%)$, attending higher education (33.20\%) and self-declared Catholics $(35.40 \%)$. Of the total, $(93.10 \%)$ of the participants declared themselves in favor of donation, despite $(71.10 \%)$ believing that there is a sale of organs and tissues. Conclusion: Campaigns and information on the subject should be intensified, containing clear and objective information, to elucidate the population on the subject, thus seeking to increase the number of effective donors in the country.

Key words: Obtaining tissues and organs, Transplants, Knowledge, Public opinion.

\footnotetext{
${ }^{1}$ Hospital de Pronto Socorro de Canoas (HPSC). Canoas - RS. *E-mail: camila.cella@hotmail.com

${ }^{2}$ Centro Universitário Ritter dos Reis (UniRitter). Porto Alegre - RS.

${ }^{3}$ Faculdades Integradas de Taquara (Faccat). Porto Alegre - RS.

${ }^{4}$ Universidade Federal do Rio Grande do Sul (UFRGS), Porto Alegre - RS.

${ }^{5}$ Santa Casa de Misericórdia de Porto Alegre, Porto Alegre - RS.

${ }^{6}$ Pontifícia Universidade Católica do Rio Grande do Sul (PUC-RS). Porto Alegre - RS.
}

SUBMETIDO EM: 7/2020

ACEITO EM: 7/2020

PUBLICADO EM: $8 / 2020$

REAS/EJCH | Vol.Sup.n.56 | e4471 | DOI: https://doi.org/10.25248/reas.e4471.2020 Página 1 de 9 


\section{RESUMEN}

Objetivo: evaluar el conocimiento y la aceptación de la población brasileña sobre el diagnóstico de muerte cerebral (BD) y la donación de órganos y tejidos para trasplantes. Métodos: Este es un estudio observacional descriptivo, transversal, realizado por conveniencia, mediante la aplicación de un cuestionario en línea, através de la Plataforma Google Forms ${ }^{\circledR}$, con preguntas basadas en las leyes reguladoras sobre donación de órganos y tejidos para trasplantes en Brasil. Resultados: 406 sujetos participaron en la investigación, con predominio de mujeres (73.60\%), con edades comprendidas entre 18 y 30 años (45.80\%), que asistieron a la educación superior (33.20\%) y católicos autodeclarados (35.40\%). Del total, (93.10\%) de los participantes se declararon a favor de la donación, a pesar de $(71.10 \%)$ creer que hay una venta de órganos y tejidos. Conclusión: Las campañas e información sobre el tema deben intensificarse, conteniendo información clara y objetiva, con el fin de dilucidar a la población sobre el tema, buscando así aumentar el número de donantes efectivos en el país.

Palabras clave: Adquisición de tejidos y órganos, Trasplantes, Conocimiento, Opinión pública.

\section{INTRODUÇÃO}

A doação de órgãos e tecidos é definida como um conjunto de ações e procedimentos que transformam um potencial doador em um doador efetivo, sendo visto como um ato solidário ao próximo. Contudo essa decisão requer discernimento e tomada de decisão por parte da família que está diante de um momento de perda, expressando sentimentos de angústia e devastação perante a despedida do familiar que acaba de morrer (BISPO CR, et al., 2016). A recusa familiar muitas vezes está condicionada a questões culturais e psicológicas, além da habilidade de comunicação do profissional de saúde que oportuniza a doação de órgão aos familiares, sendo indispensável o acolhimento nesse difícil momento, que proporciona o vínculo e consequentemente um diálogo aberto possibilitando o esclarecimento de dúvidas (SADALA MLA, 2001; SIQUEIRA MM, et al., 2016).

A doação intervivo é permitida somente entre cônjuges e parentes consanguíneos até quarto grau, sendo que pessoas fora destas condições poderão realizar o processo exclusivamente com autorização judicial, e de órgãos duplos ou que se regeneram, tais como: um dos rins, uma parte do fígado, uma parte dos pulmões, medula óssea e sangue. Já a doação de órgão com doadores falecidos, ocorre após a confirmação do diagnóstico de Morte Encefálica (ME), nos casos em que não sejam identificadas contraindicações absolutas e clínicas e com o consentimento familiar (BISPO CR, et al., 2016; VICTORINO JP e VENTURA CAA, 2017). Estes órgãos são direcionados para pacientes que aguardam em uma lista única, que é definida pela Central Estadual de Transplantes (CET) de cada estado e, controlada pelo Sistema Nacional de Transplante (SNT) (BRASIL, 2018).

Em 2017, o Conselho Federal de Medicina (CFM) publicou a Resolução no 2.1736, que definiu novos critérios para o diagnóstico da ME, sendo apontados fatores que antes não eram aprofundados na Lei no 9.434/1997 (BRASIL, 1997; CFM, 2017). O Registro Brasileiro de Transplantes (RBT) de 2019, apresentou aumento de $(6,50 \%)$ na taxa de doadores efetivos no período, resultado da crescente taxa de autorização familiar $(7,10 \%)$, e aumento na taxa de potenciais doadores em morte encefálica (5,20\%) (RBT, 2019). A efetivação do processo de doação de órgãos e tecidos para transplantes se dá inicialmente com a identificação dos potenciais doadores pelos profissionais da saúde nas Unidades de Terapia Intensiva (UTI) e Emergências (SADALA MLA, 2001). Em 2019, o Brasil teve 11.400 notificações de potenciais doadores, entretanto, por diversas causas a doação de órgãos não foi concretizada, sendo as mais frequentes: 2.674 $(40 \%)$ recusa familiar, $1.761(15 \%)$ contraindicação médica, 927 (8\%) evolução para parada cardiorrespiratória, e 865 (8\%) ME não confirmada (RBT, 2019).

Estudo realizado no Pará avaliou o conhecimento da população sobre o processo de doação de órgãos e tecidos, constatou que há insuficiência no conhecimento da legislação por parte dos profissionais da saúde, bem como dos preceitos éticos visto pela população em geral. Dos 136 participantes, 115 (84,60\%) 
declararam-se favoráveis à doação de órgãos, em contrapartida, apenas 27 (19,90\%) confiavam na capacidade dos médicos em diagnosticar corretamente a condição de ME. Esse estudo apresentou um importante resultado, ao considerar que mesmo com 109 (80,10\%) dos participantes tendo conclusões errôneas sobre o significado da $\mathrm{ME}$, grande parte ainda era favorável a doação de órgãos, trazendo a relevância de haver maiores discussões, oportunizando o acesso à informação para a população (TEIXEIRA RKC, et al., 2012).

Apesar das diversas campanhas para a conscientização da população quanto à importância da doação de órgãos e tecidos, a taxa de doadores efetivos em 2019 não atingiu o que fora previsto para o período (no ano de 2016 foram estimados escopos a serem alcançados por cada estado), apresentando 18,1 doadores por milhão de população (PMP), sendo o planejamento de doadores efetivos para 2016, de 18,5 doadores PMP, resultado esse que mostra o baixo quantitativo de doadores, considerando as necessidades da população brasileira, que acarreta em crescentes listas de espera (RBT, 2019).

Diante desse cenário, acredita-se que a escassez de debates sobre o tema, tanto durante a formação dos profissionais da saúde quanto à população em geral, impacta diretamente nas taxas de recusa para a doação de órgãos e tecidos. Nesse sentido, se faz necessário tencionar discussões sobre o assunto nos diferentes contextos profissionais e familiares, bem como a formação continuada dos profissionais de saúde para com esse tema. Assim, o objetivo desta pesquisa foi avaliar o conhecimento e a aceitação da população brasileira sobre o diagnóstico de ME e o processo de doação de órgãos e tecidos para transplantes.

\section{MÉTODOS}

Trata-se de um estudo observacional descritivo transversal, realizado por meio da aplicação de técnicas padronizadas de coleta de dados, como uso de um questionário semiestruturado, considerando a observação sistemática dos fatos importante fator para descrever determinada população ou fenômeno (GIL AC, 2017). A coleta de dados foi realizada por conveniência, através da aplicação de um questionário online, composto por vinte e duas questões semiestruturadas.

O acesso ao instrumento se deu pela Plataforma do Google Forms ${ }^{\circledR}$, baseado as perguntas em leis regulamentadoras da doação e transplante de órgãos e tecidos no Brasil e, adaptado dos instrumentos de coleta de dados utilizados por estudos anteriores (BRASIL, 1997; TEIXEIRA RKC, et al., 2012; GIL AC, 2017).

O questionário foi composto por três seções envolvendo (1) caracterização sociodemográfica; (2) conhecimentos específicos e; (3) aceitação da doação. A divulgação e convite para participação no estudo, com acesso ao questionário, se deu por compartilhamento em meios virtuais, considerando as redes sociais e endereço eletrônico. O tamanho amostral foi realizado a partir da projeção da população brasileira de 209.007.101 pessoas, segundo o Instituto Brasileiro de Geografia e Estatística em 2018 (IBGE, 2018). A partir do cálculo amostral, determinou-se a necessidade da participação de no mínimo 385 indivíduos com margem de erro de $5 \%$ e intervalo de confiança de $95 \%$.

O teste piloto foi realizado com 10 indivíduos, sendo posteriormente descartados estes dados. Os demais dados coletados serão armazenados por cinco anos no banco de dados Excel ${ }^{\circledR}$ e após este período, excluídos permanentemente da rede. O estudo seguiu os critérios éticos estabelecidos pela Resolução 466/2.012 do Conselho Nacional de Saúde (CNS), que dispõe sobre pesquisas envolvendo seres humanos, sendo aprovado pelo parecer número 2.896.904. Os pesquisadores envolvidos tiveram compromisso com a privacidade e a confidencialidade dos dados utilizados (BRASIL, 2012).

\section{RESULTADOS}

Participaram da pesquisa 406 sujeitos, sendo 299 (73,60\%) do sexo feminino e 107 (26,40\%) do sexo masculino. A faixa etária de 18 a 30 anos prevaleceu representando $186(45,80 \%)$ dos sujeitos. Em relação à escolaridade, a maioria $135(33,20 \%)$ estava cursando o ensino superior. Acerca da religião, do total da amostra, a maioria dos participantes eram católicos, seguido de espíritas e evangélicos, perfazendo 144 $(35,40 \%), 78(19,20 \%)$ e $62(15,20 \%)$, respectivamente (Tabela 1). 
Tabela 1 - Caracterização sociodemográfica dos participantes da pesquisa.

\begin{tabular}{lcc}
\hline Variáveis & $\mathbf{N}$ & $\mathbf{( \% )}$ \\
\hline Sexo & 299 & $73,6 \%$ \\
\hline Feminino & 107 & $26,30 \%$ \\
Masculino & & \\
\hline Faixa Etária & 186 & $45,80 \%$ \\
\hline 18 a 30 anos & 114 & $28,07 \%$ \\
31 a 40 anos & 42 & $10,30 \%$ \\
41 a 50 anos & 49 & $12,06 \%$ \\
51 a 60 anos & 15 & $03,60 \%$ \\
61 a 65 anos & & \\
\hline Escolaridade & 07 & $01,70 \%$ \\
\hline Ensino Fundamental Incompleto & 07 & $01,70 \%$ \\
Ensino Fundamental Completo & 19 & $04,60 \%$ \\
Ensino Médio Incompleto & 88 & $21,60 \%$ \\
Ensino Médio Completo & 55 & $13,50 \%$ \\
Ensino Superior Completo & 135 & $33,20 \%$ \\
Ensino Superior Cursando & 65 & $16,01 \%$ \\
Especialização & 18 & $04,40 \%$ \\
Mestrado & 10 & $02,40 \%$ \\
Doutorado & 02 & $00,40 \%$ \\
Pós-Doutorado & & \\
\hline Religião & 144 & $35,40 \%$ \\
\hline Católica & 78 & $19,20 \%$ \\
Espírita & 62 & $15,20 \%$ \\
Evangélica & 35 & $08,60 \%$ \\
Prefiro não opinar & 33 & $08,10 \%$ \\
Não acredito em nenhuma religião & 26 & $06,40 \%$ \\
Umbanda & 13 & $03,20 \%$ \\
Ateu & 03 & $00,70 \%$ \\
Me identifico com várias religiões & 04 & $00,90 \%$ \\
Matriz africana & 03 & $01,20 \%$ \\
Budismo & 05 & \\
Outras* & & \\
\hline & & \\
\hline
\end{tabular}

Legenda: Dados expressos em frequência absoluta e relativa. * Holística, Adventista, Judaica, Igreja de Jesus Cristo dos Santos dos Últimos Dias.

Fonte: Souza CC, et al., 2020.

Em relação aos conhecimentos específicos frente ao processo de doação de órgãos e tecidos, 277 participantes $(68,20 \%)$ acreditam que o consentimento para doação de órgãos e tecidos no Brasil seja realizado por meio da autorização familiar, $82(20,20 \%)$ pelo registro do desejo no documento de identificação, $31(7,60 \%)$ no registro em cartório e, $16(3,90 \%)$ não souberam opinar. Quanto ao diagnóstico médico de ME, 199 (49\%) confiam parcialmente no resultado e 212 (52,20\%) pressupõem que seja quando o paciente está "apenas com o cérebro morto", mantendo as demais funções do corpo, confundindo-se com o coma.

Destaca-se que, 291 participantes $(71,10 \%)$ pressupõem que haja comercialização de órgãos no país, sendo que destes, $49(16,80 \%)$ têm idade entre 18 a 30 anos, $35(12,02 \%)$ estão cursando o ensino superior e $29(9,60 \%)$ são católicos. Entretanto, 278 (68,50\%) presumem que as chances de recebimento de um órgão não dependem do poder aquisitivo e $124(30,50 \%)$ acreditam que os mais ricos seriam aqueles com maior chance de receber o transplante. Por fim, em relação aos tipos de doadores conhecidos, $326(80,30 \%)$ responderam doador em ME, $274(67,50 \%)$ doador vivo e $33(8,10 \%)$ pessoas não souberam responder (Tabela 2). 
Tabela 2 - Conhecimento dos participantes sobre a Morte Encefálica e a Doação de Órgãos e tecidos.

\begin{tabular}{|c|c|c|}
\hline Variáveis & $\mathbf{N}$ & $(\%)$ \\
\hline \multicolumn{3}{|l|}{ Consentimento para Doação } \\
\hline Autorização familiar & 277 & $68,30 \%$ \\
\hline Registro do desejo em documento de identificação & 82 & $20,20 \%$ \\
\hline Registro em cartório do desejo & 31 & $07,60 \%$ \\
\hline Não soube informar & 16 & $03,90 \%$ \\
\hline \multicolumn{3}{|l|}{ Comercialização de Órgãos } \\
\hline Sim & 291 & $71,10 \%$ \\
\hline Não & 84 & $20,70 \%$ \\
\hline Não soube informar & 31 & $07,60 \%$ \\
\hline \multicolumn{3}{|l|}{ Perfil Aquisitivo com Chances de Receber um Órgão } \\
\hline Independente do poder aquisitivo & 279 & $68,50 \%$ \\
\hline Ricos & 124 & $30,50 \%$ \\
\hline Pobres & 04 & $01,00 \%$ \\
\hline \multicolumn{3}{|l|}{ Pessoa Considerada em Morte Encefálica } \\
\hline Só com o cérebro morto & 212 & $52,20 \%$ \\
\hline Morta & 165 & $40,60 \%$ \\
\hline Não soube informar & 19 & $04,70 \%$ \\
\hline Viva & 10 & $02,50 \%$ \\
\hline \multicolumn{3}{|c|}{ Confiança no Diagnóstico Médico de Morte Encefálica } \\
\hline Confiança parcial & 199 & $49,00 \%$ \\
\hline Confiança plena & 192 & $47,30 \%$ \\
\hline Sem confiança & 15 & $03,70 \%$ \\
\hline \multicolumn{3}{|l|}{ Tipos de doadores } \\
\hline Doador em morte encefálica & 326 & $80,30 \%$ \\
\hline Doador vivo & 274 & $67,50 \%$ \\
\hline Não soube informar & 33 & $08,10 \%$ \\
\hline
\end{tabular}

Legenda: Dados expressos em frequência absoluta e relativa.

Fonte: Souza CC, et al., 2020.

Ao serem questionados sobre quais órgãos e tecidos poderiam ser doados em vida, o rim, a medula óssea, o sangue e o fígado foram os mais citados, totalizando $369(90,90 \%), 341(84 \%), 316(77,80 \%)$ e 227 $(55,90 \%)$, respectivamente. Quanto à doação após a morte, as respostas mais frequentes foram 375 $(92,40 \%)$ o coração, $359(88,40 \%)$ as córneas, $341(84 \%)$ o pulmão, $332(81,80 \%)$ o rim, $318(78,30 \%)$ o fígado e $299(73,60 \%)$ a pele (Figura 1).

Figura 1 - Opinião dos participantes sobre quais órgãos que podem ser doados em vida e pós-morte.

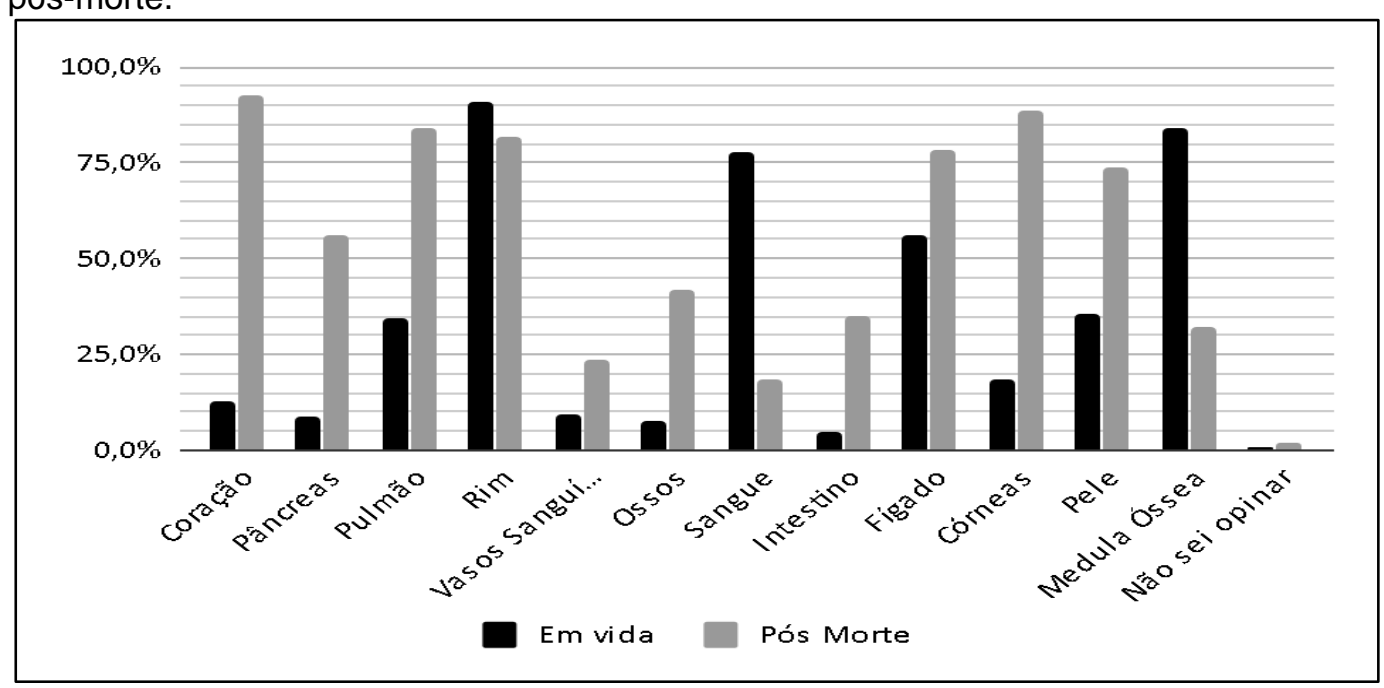

Legenda: Dados expressos em frequência absoluta e relativa.

Fonte: Souza CC, et al., 2020. 
No que diz respeito às aceitações pessoais para a doação de órgãos, $378(93,10 \%)$ responderam que seriam favoráveis após a morte e $23(5,70 \%)$ não tinham opinião formada, $03(0,70 \%)$ resolveram não opinar e $02(0,50 \%)$ se disseram não favoráveis a doação. Quanto aos motivos dos 2 respondentes não serem favoráveis a doação, um teria sido por medo de mutilação do corpo e o outro por desconfiança de que os órgãos seriam distribuídos para quem tem mais dinheiro (Tabela 3).

Tabela 3 - Opinião pessoal dos participantes sobre a doação de órgãos e tecidos para transplantes.

\begin{tabular}{|c|c|c|}
\hline Variáveis & $\mathbf{N}$ & $(\%)$ \\
\hline \multicolumn{3}{|l|}{ Favorável a Doacão } \\
\hline Sim & 378 & $93,10 \%$ \\
\hline Não tenho opinião formada & 23 & $05,70 \%$ \\
\hline Prefiro não opinar & 03 & $00,70 \%$ \\
\hline Não & 02 & $00,50 \%$ \\
\hline \multicolumn{3}{|l|}{ Motivo de ser favorável a adoção } \\
\hline Salvar vidas/Ajudar o próximo & 356 & $94,20 \%$ \\
\hline O órgão não é útil para o falecido & 154 & $40,70 \%$ \\
\hline Posso precisar de um transplante no futuro & 103 & $27,20 \%$ \\
\hline Familiar já precisou de um transplante & 36 & $09,50 \%$ \\
\hline \multicolumn{3}{|l|}{ Motivo de não ser favorável a doação* } \\
\hline Medo de mutilação do corpo & 01 & $50,00 \%$ \\
\hline Os órgãos vão para quem tem mais dinheiro & 01 & $50,00 \%$ \\
\hline \multicolumn{3}{|c|}{ Comunicação aos familiares sobre o desejo de ser doador ${ }^{\star \star}$} \\
\hline Sim & 279 & $73,40 \%$ \\
\hline Não & 101 & $26,60 \%$ \\
\hline \multicolumn{3}{|c|}{ Autorização da doação de órgãos de familiares de primeiro grau } \\
\hline Sim & 338 & $83,30 \%$ \\
\hline Não tenho opinião formada & 55 & $13,50 \%$ \\
\hline Não & 13 & $03,20 \%$ \\
\hline
\end{tabular}

Legenda: Dados expressos em frequência absoluta e relativa. ${ }^{*} \mathrm{O}$ quantitativo de respostas finais aumentou devido ao número de questões múltipla escolha presentes no estudo. ${ }^{* *}$ Respostas obtidas somente dos participantes que responderam "sim" ou "não" na questão sobre ser a favor da Doação de Órgãos e Tecidos. Fonte: Souza CC, et al., 2020.

Dentre todos os participantes, $279(73,40 \%)$ referiram já ter informado o desejo de doação aos seus familiares. As justificativas de quem se posicionou a favor da doação foi 356 (94,20\%) para "salvar vidas/ajudar o próximo", 154 (40,70\%) porque "o órgão não é útil para o falecido", 103 (27,20\%) porque "pode precisar no futuro" e 36 (9,50\%) porque "um familiar já precisou de um transplante".

Ao serem questionados quanto ao consentimento da doação de órgãos e tecidos de seus familiares, 338 $(83,30 \%)$ responderam que autorizariam, 55 (13,50\%) não tinham opinião formada e $13(3,20 \%)$ não doariam. Dentre os que não doariam os órgãos de seus familiares, 05 (38,40\%) têm idade entre 31 a 40 anos, 04 $(30,70 \%)$ estão cursando o ensino superior e 09 (69,20\%) se declararam católicos.

É importante ressaltar que 101 (26,60\%) participantes não haviam conversado com seus familiares sobre a doação de órgãos, podendo estar associado com o resultado do questionamento se eles sabiam como fazer para ser um doador, quando $129(31,7 \%)$ declararam que não sabiam como fazer, inferindo que, se os participantes não tinham o conhecimento de que o familiar seria o responsável pela autorização da doação de órgãos, logo não teriam motivos para conversar com os mesmos sobre o assunto. Dos $124(30,50 \%)$ que acreditam que os mais ricos seriam aqueles com maior chance de receber o transplante $61(49,20 \%)$ têm idade entre 18 a 30 anos, $43(35,40 \%)$ estavam cursando o ensino superior e 41 (33,06\%) se declaram católicos.

Referente à mídia e abordagem sobre o assunto, 292 (71,9\%) dos respondentes informaram já ter participado de alguma palestra e/ou curso sobre a temática. Ao serem questionados se o assunto deveria ser mais abordado $395(97,3 \%)$ responderam que sim através da televisão, $340(83,70 \%)$ nas escolas, $329(81 \%)$ por meio de palestras, $326(80,30 \%)$ na atenção primária e $281(69,20 \%)$ disseram que o jornal seria a melhor forma de abordagem. 


\section{DISCUSSÃO}

O estudo proporcionou um valioso material para embasar amplos debates sobre situações bastante específicas, referentes ao conhecimento da população para a doação de órgãos para transplantes. 0 questionamento de como se tornar um doador revelou que 129 participantes $(31,70 \%)$ não sabem como expressar seu desejo em vida, enquanto $101(26,60 \%)$ dos participantes não teriam conversado com seus familiares sobre a doação de órgãos. Situação essa que remete a necessidade de mais diálogo com a população, propiciando a discussão e esclarecimentos sobre esse tema, oportunizando que a família conheça o desejo de seus familiares diante da possibilidade da doação de órgãos e tecidos para transplantes, respeitando esse desejo.

Paralelamente a essa necessidade, a formação profissional sobre ME e doação de órgãos mostra-se fundamental, uma vez que para conseguirmos discutir sobre o assunto, precisamos ter conhecimento sobre o tema a fim de oportunizar a reflexão da importância da doação de órgãos para transplantes com os que não atuam na área, mas também para a reciclagem daqueles que já exercem suas atividades frente a doação de órgãos para transplantes. Estudo realizado no Rio Grande do Sul (RS), que apresentou resultados referentes a um curso sobre ME e doação de órgão para profissionais de saúde, quando, durante atividade de aprendizagem, os profissionais que não atuavam em Organizações de Procura de Órgãos (OPOs) ou Comissão Intra-Hospitalar de a Doação de Órgãos e Tecidos para Transplantes (CIHDOTT) tiveram melhores resultados do que aqueles que, na teoria teriam mais experiência, ressaltando a importância da busca por conhecimento e formação continuada por todos os profissionais atuantes ou não no processo de doação de órgãos para transplantes (LYSAKOWSKI S, et al., 2019).

Além disso, a comunicação dos profissionais da saúde para com os familiares precisa ser aprimorada, visando a eficácia da compreensão sobre o tema, bem como a efetivação do acolhimento diante desse momento de perdas (MENEZES NP, et al., 2018). Essa necessidade de educação dos profissionais para com esse tema é evidenciada quando $199(49 \%)$ dos participantes relataram que confiam parcialmente no diagnóstico de ME e $212(52,20 \%)$ acreditam que a ME significa que apenas o cérebro está morto, mostrando que essa população ainda não tem o esclarecimento necessário sobre o assunto, mesmo se considerarmos que $(71,90 \%)$ dos participantes já teriam realizado algum tipo atividade que objetivasse a discussão do tema.

Gonçalves TB, et al. (2012), realizou um estudo que também avaliou o conhecimento da população sobre $\mathrm{ME}$, constatou que a maioria dos participantes $(48,60 \%)$ acreditavam que a pessoa estava somente com o cérebro morto e que teria condição de viver, sucedido por $(28,40 \%)$ que acreditavam que o paciente estaria parcialmente vivo, com condições de viver se tratado. Ao abordar essa temática pode-se esclarecer à população o conceito de ME, sendo de extrema importância esta compreensão para o aumento das taxas de doação de órgãos e tecidos.

Ainda sobre a necessidade de informação para a população, a comercialização de órgãos no Brasil foi apontada por $291(71,10 \%)$ dos participantes, e 124 (30,50\%) informaram acreditar que aqueles mais ricos teriam maiores chances de receber um transplante. Dados esses que mostram o desconhecimento acerca das diversas etapas do processo de ME e doação de órgãos, trazendo a reflexão da importância de ampliar as discussões atendendo as necessidades da população, pois muitas vezes os assuntos abordados em palestras e campanhas, não são aquelas que o público tem dúvidas e quer saber mais.

Estudo semelhante, realizado em 2016, também avaliou o conhecimento de docentes de enfermagem sobre a aceitação da doação, e encontrou resultado diferente, identificando que apenas $2(4,50 \%)$ dos respondentes declararam acreditar que exista a comercialização de órgãos na realidade brasileira (FREIRE ILS, et al., 2016).

Para a Organização Mundial de Saúde (OMS) o comércio de órgãos configura-se como um ato de violação da carta universal dos direitos humanos e da constituição (BRASIL, 2008). A comercialização de órgãos é vedada, conforme o artigo 46 do Conselho Federal de Medicina (CFM), bem como qualquer tipo de participação médica ou da equipe cirúrgica na compra ou venda de órgãos e tecidos para comercialização (SILVA TRB, et al., 2016; CFM, 2017).

REAS/EJCH | Vol.Sup.n.56 | e4471 | DOI: https://doi.org/10.25248/reas.e4471.2020 Página 7 de 9 
A Declaração de Istambul sobre Tráfico de Órgãos e Turismo de Transplante (2008), contou com a presença de mais de 150 representantes de organismos científicos e médicos, membros do governo, cientistas sociais e especialistas em questões éticas para abordar os problemas crescentes da venda e tráfico de órgãos no contexto global. A presente declaração representa um consenso que todos os países necessitam de um enquadramento jurídico e profissional para reger as atividades de doação e de transplante de órgãos, bem como de um sistema de supervisão regulamentar transparente, que preserve a segurança de doadores e receptores, aplicando normas e restringindo práticas que não sejam éticas

Mesmo havendo um expressivo número de participantes em nossa pesquisa, que acreditavam em situações desfavoráveis a doação, apenas $68(16,70 \%)$ expressaram que não doariam os órgãos para transplantes ou que não sabiam informar sobre essa decisão, o que vai de encontro aos dados disponibilizados pela Associação Brasileira de Transplantes de Órgãos (ABTO) no ano de 2019, quando 40\% das famílias não autorizaram a doação de órgãos (RBT, 2019).

Estudo realizado em 2015, que avaliou o conhecimento da população de Goiás sobre o processo de doação de órgãos para transplantes, evidenciou que a maioria dos participantes foram favoráveis a doação de órgãos e tecidos $43(86 \%)$ sendo somente $02(4 \%)$ com posicionamento contrário (FELIX MB e SANTOS WL, 2015). Outro estudo realizado em 2015, corroborou com o anterior ao mostrar que estudantes de nível técnico e superior de Enfermagem, quando questionados aos aspectos éticos e legais da doação, 111 $(91,70 \%)$ responderam de forma positiva a doação de órgãos, enquanto apenas $10(8,30 \%)$ desses participantes foram desfavoráveis (FREIRE ILS, et al., 2015). Tais dados mostram que a formação profissional pode influenciar na decisão para a doação de órgãos e tecidos, entendendo que esses estariam mais familiarizados com o tema, além de possuírem maior conhecimento prático e técnico sobre o assunto, indo parcialmente de encontro com estudo realizado em 2019, que mostraram pior desempenho em uma atividade, durante curso sobre ME e doação de órgãos, dos profissionais já atuantes nessa área específica (LYSAKOWSKI S, et al., 2019).

Quanto à religião, no presente estudo a católica 144 (35,40\%) e o espiritismo 78 (19,10\%) foram as mais citadas. Estudos anteriores com a mesma temática foram ao encontro deste, com a maioria dos participantes católicos (TEIXEIRA RKC, et al., 2012; FELIZ MB e SANTOS WL, 2015; FREIRE ILS, et al., 2015; CARLOS DS, et al., 2016). Pesquisa que objetivou analisar se a religião interfere na decisão do doador e/ou da família de consentir com a doação de órgãos e com o processo de captação e transplante, constatou que nenhuma religião é de forma absoluta contrária à doação e, ressalta que é importante e primordial a equipe de saúde, em especial a Enfermagem, com a conquista de espaço profissional no processo de captação de órgãos, ter um mínimo entendimento e consciência da diversidade cultural e religiosa, a fim de nortear uma conduta em saúde para uma abordagem assertiva no momento importante de acolher as decisões de pacientes e suas famílias (FERAZZO S, et al., 2011).

Tendo em vista as evidências relacionadas à mídia e abordagem sobre o assunto a maioria $292(71,90 \%)$ dos respondentes dizem já ter participado de alguma palestra, porém 395 (97,30\%) acreditam que este assunto poderia ser mais abordado na televisão, escolas e palestras. Dados apresentados em 2018 pelo Ministério da Saúde (MS) reforçam o quanto é importante a União, estados e municípios investirem cada vez mais em ações de conscientização da população, com ênfase aos familiares e profissionais de saúde. As campanhas do MS de incentivo à doação de órgãos, destacam a importância de aprofundamento do tema na sociedade (BRASIL, 2018).

Houveram algumas limitações neste trabalho, decorrentes do modo em que foi realizado, visto que a coleta de dados virtuais demonstra que, apesar de não haver diferença entre resultados coletados com o questionário impresso, há a possibilidade de privilégio a pessoas com maiores níveis de instrução, uma vez que aqueles que não conseguem acessar as mídias foram suprimidos dessa pesquisa (FALEIROS F, et al., 2016). Além disso, viés de memória e confusão podem estar presentes, uma vez que fora instigada a reflexão sobre ações e decisões diante de situações difíceis e de familiares (JEKEL JF, et al., 2006). Os potenciais vieses decorrentes dessas limitações são reconhecíveis ainda que seja possível obter um panorama do conhecimento da população brasileira sobre a doação de órgãos e tecidos de modo bastante ágil. 


\section{CONCLUSÃO}

Diante do exposto, percebe-se que a pergunta de pesquisa foi respondida, devendo ser considerada a relevância de estudos semelhantes a fim de demonstrar a necessidade de aperfeiçoamento e educação continuada para os profissionais da saúde e população, observando que o conhecimento sobre o tema pode estar diretamente relacionado à possibilidade de aumento no número de doação de órgãos e tecidos, proporcionando assim o incremento nos registros de transplantes e, consequentemente ganhos para toda a sociedade. Propõe-se a partir da análise, novas estratégias de ensino e promoção do assunto, bem como conhecer a população alvo e o que esses querem saber, direcionando assim a educação para o esclarecimento de possíveis dúvidas e a desmistificação de estigmas.

\section{REFERÊNCIAS}

1. BISPO CR, et al. Doação de órgãos: Uma perspectiva de graduandos de enfermagem. Rev. Bioét., Brasília, 2016; 24(2):386-394.

2. BRASIL, 2008. Ministério da Saúde. In: Dicas em Saúde. Disponível em: http://bvsms.saude.gov.br/bvs/dicas/146morte_encefalica.html Acesso em: 18 nov. 2019

3. BRASIL, 2018. Ministério da Saúde. In: Doação de Órgãos: transplantes, lista de espera e como ser doador. Disponível em: http://portalms.saude.gov.br/saude-de-a-z/doacao-de-orgaos Acesso em: 30 nov. 2018

4. BRASIL. Lei no 9.434 , de 4 de fevereiro de 1997. Dispõe sobre a remoção de órgãos, tecidos e partes do corpo humano para fins de transplante e tratamento e dá outras providências [Internet]. Diário Oficial da União: seção 1, Brasília, DF, ano 139, 5 fev. 1997: 2191.

5. BRASIL. Resolução n. 466 de 2012, Normas para pesquisa envolvendo seres humanos. Brasília, DF, 2012.

6. CARLOS DS, et al. Conhecimentos dos acadêmicos de Enfermagem sobre Doação de Órgãos e Tecidos. Conversas Interdisciplinares, Rio Grande do Sul, 2016; 11(1)

7. CONSELHO FEDERAL DE MEDICINA. Resolução CFM n. 2.1736, de 23 de novembro de 2017. Critérios para diagnóstico de Morte Encefálica. Diário Oficial da União: seção 1, Brasília, DF, 23 nov. 2017:50-275.

8. DECLARAÇÃO DE ISTAMBUL SOBRE TRÁFICO DE ÓRGÃOS E TURISMO DE TRANSPLANTE. Disponível em: http://www.declarationofistanbul.org/images/stories/translations/doi_portuguese.pdf Acesso em: $18 \mathrm{dez} .2018$

9. FALEIROS F, et al. Uso de questionário online e divulgação virtual como estratégia de coleta de dados em estudos científicos. Texto \& Contexto Enfermagem, Florianópolis, 2016; 25(4)

10. FELIX MB, SANTOS WL. Conhecimento da população do município de Valparaíso de Goiás sobre o processo de doação de órgãos para transplantes. REVISA, Goiás, 2015; 4(1): 3-10

11. FERAZZO S, et al. Crença religiosa e doação de órgãos e tecidos: revisão integrativa da literatura. Revista de Enfermagem da UFSM, Rio Grande do Sul, 2011; 1(3):449-460

12. FREIRE ILS, et al. Aspectos éticos e legais da doação de órgãos: visão dos estudantes de enfermagem. Revista de Enfermagem do Centro-Oeste Mineiro. Rio Grande do Norte, 2015; 5(2)

13. FREIRE ILS, et al. Aceitação e conhecimento de docentes de enfermagem sobre a doação de órgãos e tecidos. Rev. Enferm. UERJ, Rio de Janeiro, 2016; 24(1): 15561

14. GIL AC. Como Elaborar Projetos de Pesquisa. 6를. Ed. Atlas. São Paulo: Ed. Atlas, 2017.

15. GONÇALVES TB, et al. Avaliação do conhecimento da população sobre morte encefálica. Rev Bras Clin. Med., São Paulo, 2012; 10(4):318-21

16. INSTITUTO BRASILEIRO DE GEOGRAFIA E ESTATíSTICA - IBGE, 2018. Disponível em: https://www.ibge.gov.br/apps/populacao/projecao/box_popclock.php Acesso em: 11 mai. 2018

17. JEKEL JF, et al. Epidemiologia, bioestatística e medicina preventiva. In: Epidemiologia, bioestatística e medicina preventiva, ARTMED. Porto Alegre, 2006; 81p.

18. LYSAKOWSKI S, et al. Formação de Recursos Humanos na Captação de Órgãos para Transplantes: Ensino à Distância (EaD) [Internet]. Res. Soc. Dev. 2019; 8 (1): e581510 ISSN 2525 - 3409 | DOI: http://dx.doi.org/10.33448/rsd - v8i1.510

19. MENEZES NP, et al. Comunicação de morte encefálica a familiares: levantamento com profissionais de saúde. Rev. SBPH, Rio de Janeiro, 2018, 21(1):192-217

20. REGISTRO BRASILEIRO DE TRANSPLANTES DE ÓRGÃOS (ABTO), 2019. Ano XXV (4). São Paulo, ABTO. Disponível em: http://www.abto.org.br/abtov03/Upload/file/RBT/2019/RBT-2019-leitura.pdf Acesso em: 09 abr. 2020.

21. SADALA MLA. A experiência de doar órgãos na visão de familiares de doadores. J Bras Nefrol, 2001; 23(3):143-51.

22. SILVA TRB, et al. Transplantes de Órgãos: A mesma vida em corpos diferentes. Revista Visão Universitária, Mato Grosso do Sul, 2016; 1(1)

23. SIQUEIRA MM, et al. Indicadores de eficiência no processo de doação e transplante de órgãos: revisão sistemática da literatura. Revista Panamericana de Salud Pública, 2016; 40:90-97

24. TEIXEIRA RKC, et al. A intenção de doar órgãos é influenciada pelo conhecimento populacional sobre morte encefálica? Rev. bras. ter. intensiva, São Paulo, 2012, 24(3):258-262.

25. VICTORINO JP, VENTURA CAA. Doação de órgãos: tema bioético à luz da legislação. Revista Bioética, 2017; 25(1). 